Is there any Need to Visit a Dentist Every Six Months?

\section{Manali Panjwani*}

Department of Dentistry, Senior Resident Doctor at Clove Dental, Telangana, India

*Corresponding Author: NManali Panjwani, Department of Dentistry, Senior Resident Doctor at Clove Dental, Telangana, India.

The answer is always yes.

\section{Here's why}

You brush your teeth daily (I hope) but even after brushing a layer of deposits known as plaque continues to form on the surface of your tooth. These layers of plaque hardens to form calculus and if calculus stays for longer period of time they tend to cause gum bleeding and gum infection.

Conclusion: Cleaning is advisable every 6 months to maximum 1 year so that you can be free from gum infection, bad breath and bleeding gums.
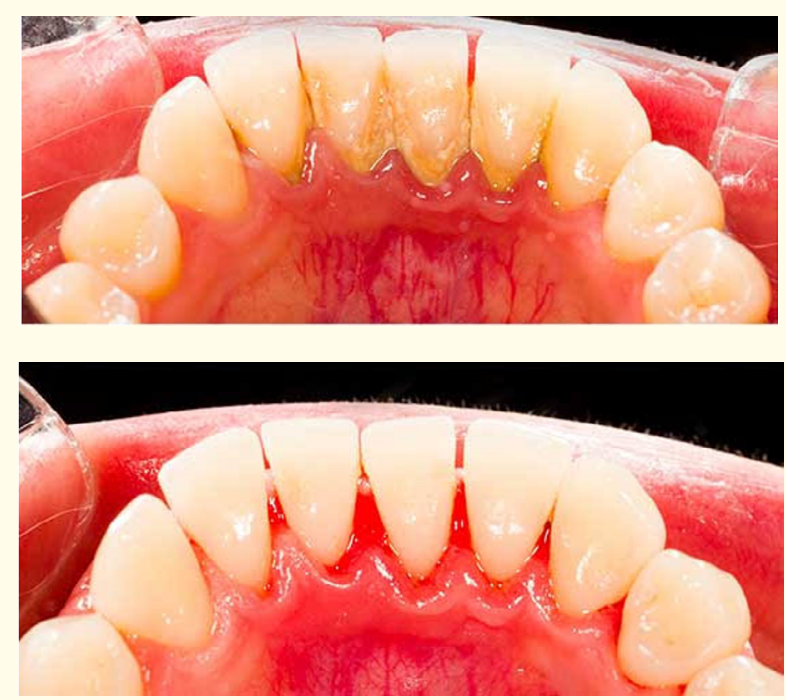

Figure 1: Before and after cleaning.
Received: April 16, 2021

Published: May 01, 2021

(C) All rights are reserved by Manali Panjwani.

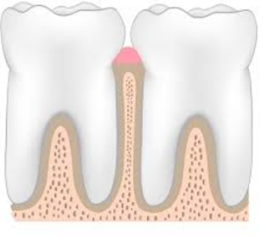

1. Healthy

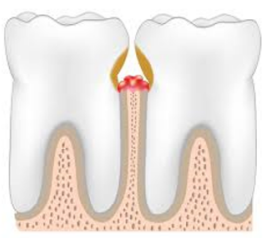

3. Periodontal pockets

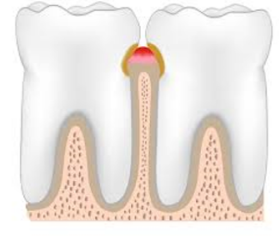

2. Gingivitis

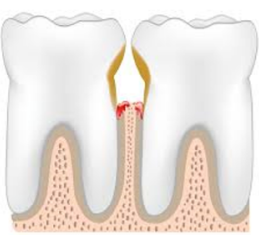

4. Periodontitis

\title{
Stages Of Gum Disease
}

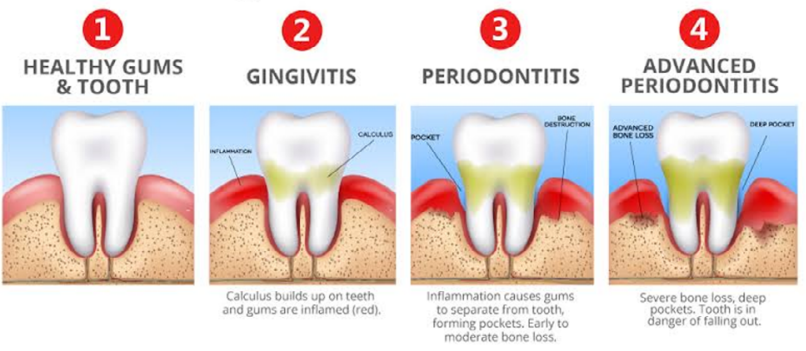

Figure 2: Stages of gum infection.

Whenever you notice any black dot on the surface of your tooth that is a cavity. The cavity that is just started and until you don't get that cavity cleaned and filled it is increasing in downward direction. 
Conclusion: If the dentist catch the cavity in early stages it can easily be cleaned and filled without causing any pain (It even saves your money of having root canal treatment).
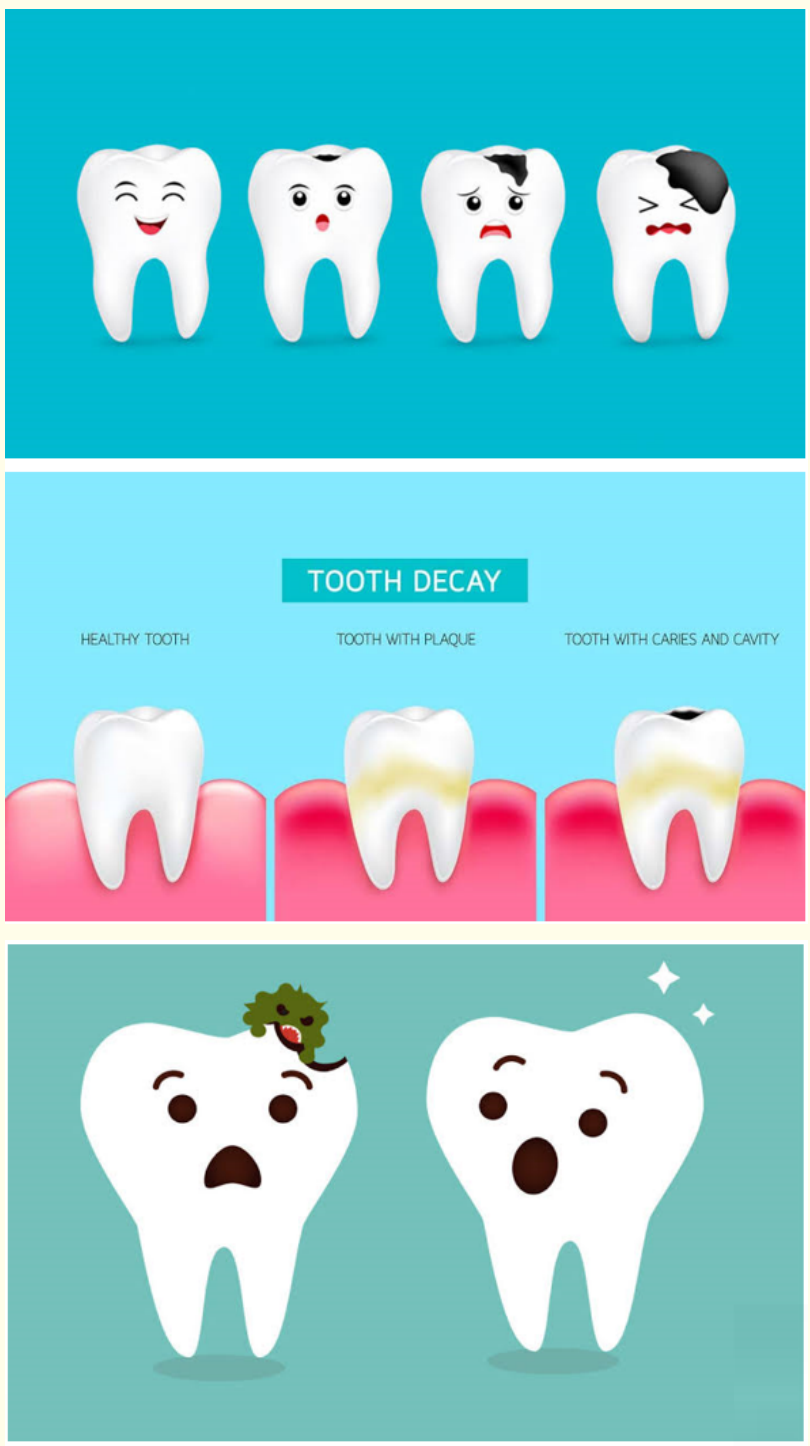

Figure 3: Stages of tooth decay.

Whenever there is pain in your tooth or any sensation to hot or cold that means your cavity is now touching your nerve but in this case if you make an early visit to your dentist, the tooth can still be saved.

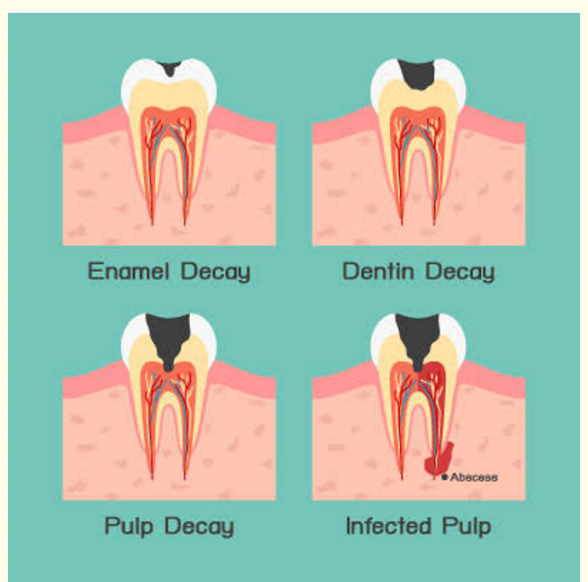

Figure 4: Caries reaching nerves.

Conclusion: If you delay the visits to your dentist the chances of saving the tooth decreases and then in severe infection the dentist has to remove the tooth and go for replacement which is again a costlier and longer procedure.

In the case of children as well regular visits to the dentist can save all later complications.
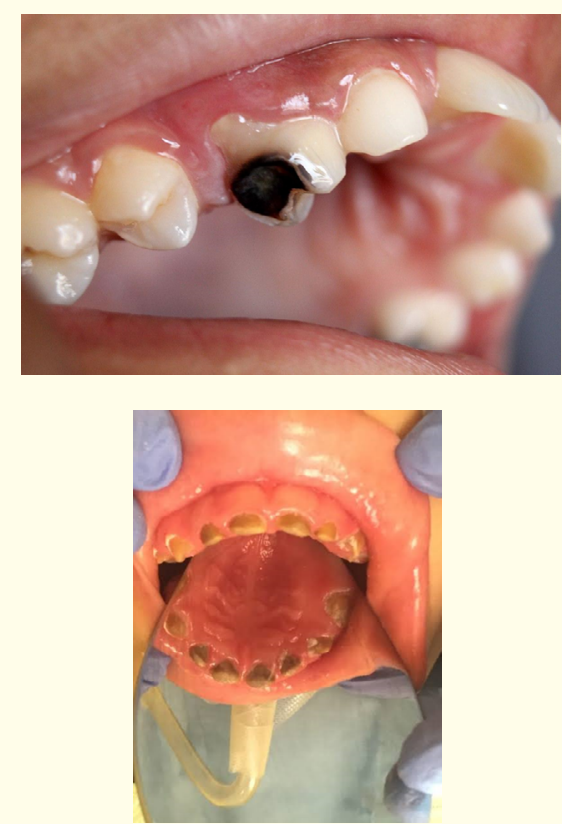


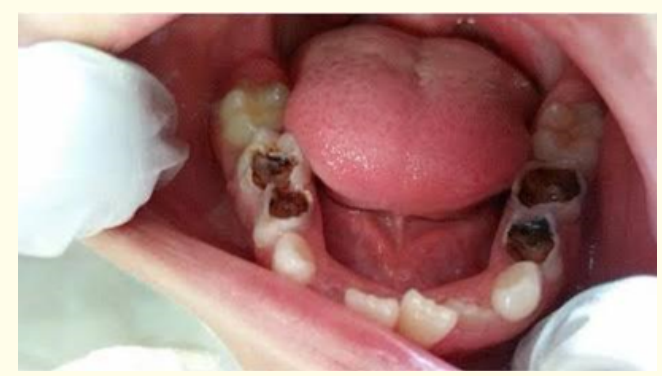

Figure 5

In conclusion it is a big yes that we need to visit the dentist every six months so that we can be aware of oral hygiene and keep it maintained.

\section{Assets from publication with us}

- Prompt Acknowledgement after receiving the article

- Thorough Double blinded peer review

- Rapid Publication

- Issue of Publication Certificate

- High visibility of your Published work

Website: www.actascientific.com/

Submit Article: www.actascientific.com/submission.php

Email us: editor@actascientific.com

Contact us: +919182824667 